\title{
Initial and east cave breakthrough events at Palabora Mining Company
}

\author{
S.N. Glazer Mine Seismology Consultant, South Africa \\ P.A. Townsend Palabora Mining Company, South Africa
}

\begin{abstract}
Understanding cave induced seismicity is important to better understanding the processes of block cave mining. This seismicity is a natural process indicating that the cave is progressing and is connected with rock mass fracturing ahead of the undercut and propagating cave. The space and time distribution of seismicity, as well as changes in their source parameters over time, are directly associated with what is happening in the rock mass around the cave and underground mining infrastructure. The initial cave breakthrough into the overlying open pit took place in May 2004 while the east breakthrough took place during the months of May and June 2008. There is a great deal of similarity as regards stress changes (as indicated by the energy index time histories), migration of seismicity, seismic energy release as well as seismic deformation patterns, with respect to the two breakthrough events. There are also some differences but they are easy to explain as the initial breakthrough took place 25 months after the stress caving process was initiated while in case of the east breakthrough, this time span had increased by a further four years. The continuous caving process during these four additional years had to significantly change the conditions of the rock mass around the cave that resulted in these differences. The energy index time histories for the two breakthrough events are very similar, indicating a stress increase prior to the breakthrough with a rapid stress release post-breakthrough. The main differences relate to the stress levels. Based on the energy index time histories the stress levels prior to the initial breakthrough were higher than those prior to the east breakthrough. The rapid stress release period in both cases was about six times shorter than the period during which the stresses were high. In both cases the pillar failure, and thereafter the breakthrough, resulted in major changes in the stress patterns around the mine. After the failure of the crown pillar larger size seismic energy releases started to appear below the extraction level. When the east pillar failed and broke through there were also some larger seismic energy releases taking place below the extraction level. In both cases the two breakthrough events resulted in an increase in the seismic hazard. The analysis presented shows that not only can seismic data analysis be successfully used to monitor the caving process, but also confirms the reliability of the process.
\end{abstract}

\section{Introduction}

The Palabora Mining Company (PMC) was founded in 1956 and open pit mining commenced in 1966 with production increasing to 82,000 tpd prior to cessation of pit mining operations in 2002. In total, some $960 \mathrm{Mt}$ of ore and 1,300 Mt of waste have been mined. The final pit depth was approximately $819 \mathrm{~m}$ deep with interramp slope angles ranging from $37^{\circ}$ in the upper weathered lithologies to approximately $58^{\circ}$ in the competent constrained ground toward the base of the pit. The ore body is an elliptical shaped, vertically dipping volcanic pipe measuring $1,400 \times 800 \mathrm{~m}$ in plan with possible resources estimated to extend to at least $1,800 \mathrm{~m}$ below surface.

The development of a nominal 30,000 tpd block cave operation was approved in 1996. Shaft sinking commenced in late 1996 and target production was attained in 2005. The development of the underground block cave operation by PMC has successfully extended the life of its operation by some 17 years.

The caving process of the underground block cave was initiated early in 2002 . The crown pillar between the cave and the open pit was presumed to have failed by the end of 2002, which is only about eight months after the caving process was initiated. By "failed" it is meant that the crown pillar was at that time fractured to the extent that it was no longer generating seismicity and no longer capable of transmitting stresses. The failed nature of the crown pillar was confirmed when there was almost immediate transmission of storm water 
through the pillar in early 2003. Figure 1 shows the PMC mine in a vertical W-E plan with the estimated cave back position at the end of 2002. The maximum elevation of the cave at the end of 2002 was at $-600 \mathrm{~m}$ which would indicate that at that time the crown pillar would have still been about $200 \mathrm{~m}$ thick. Figure 1 also shows the seismicity that was recorded during December 2002 and January 2003. There was much more seismicity recorded at the east than at the west side of the cave. This is because at that time seismic coverage at the west was still very poor. This was only rectified by the end of 2003 . This figure illustrates the failed nature of the crown pillar showing that there was no seismicity recorded between the maximum cave elevation and the lowest elevations of the open pit.

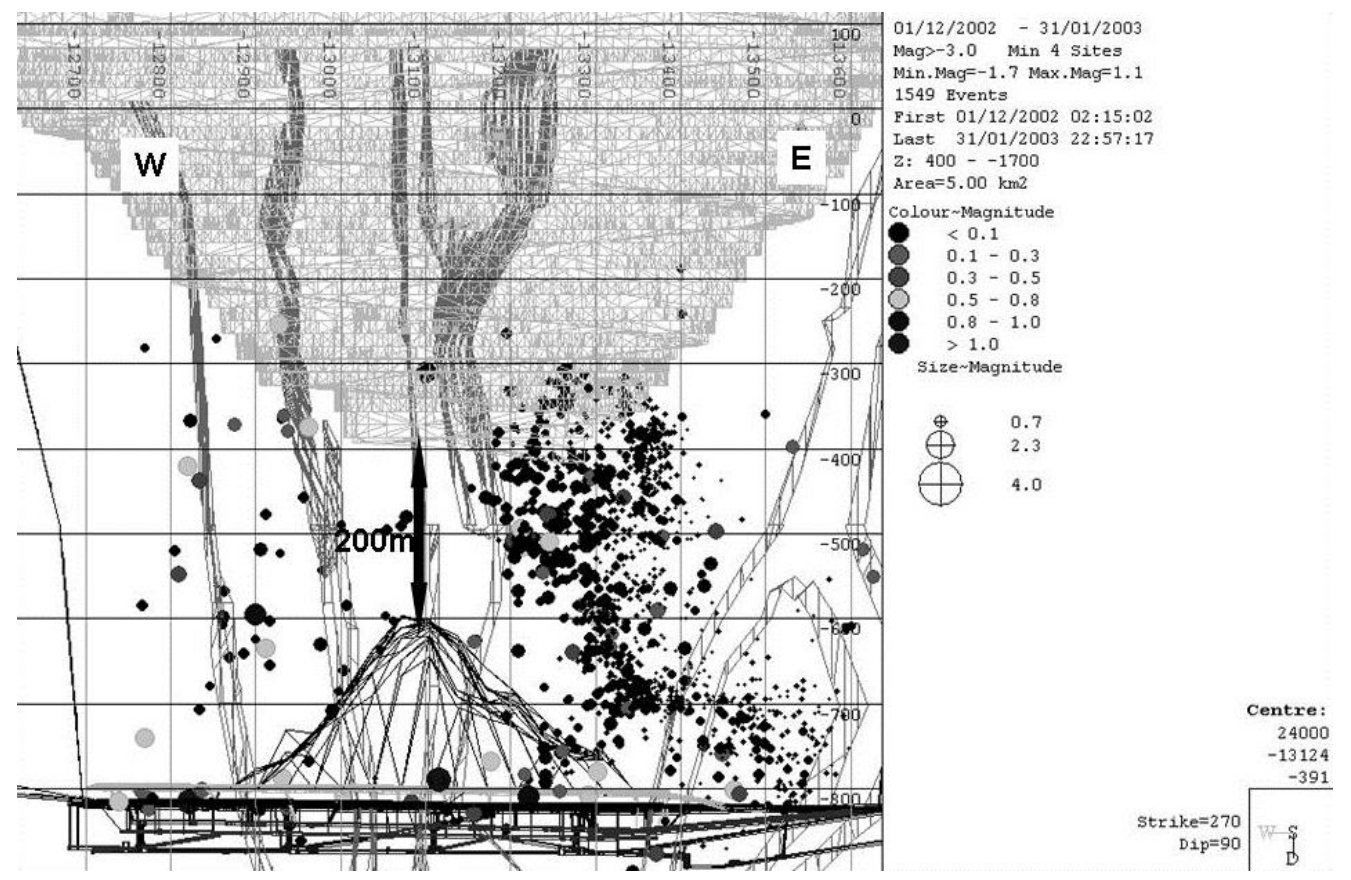

\section{Figure 1 Estimated cave back position at the end of 2002}
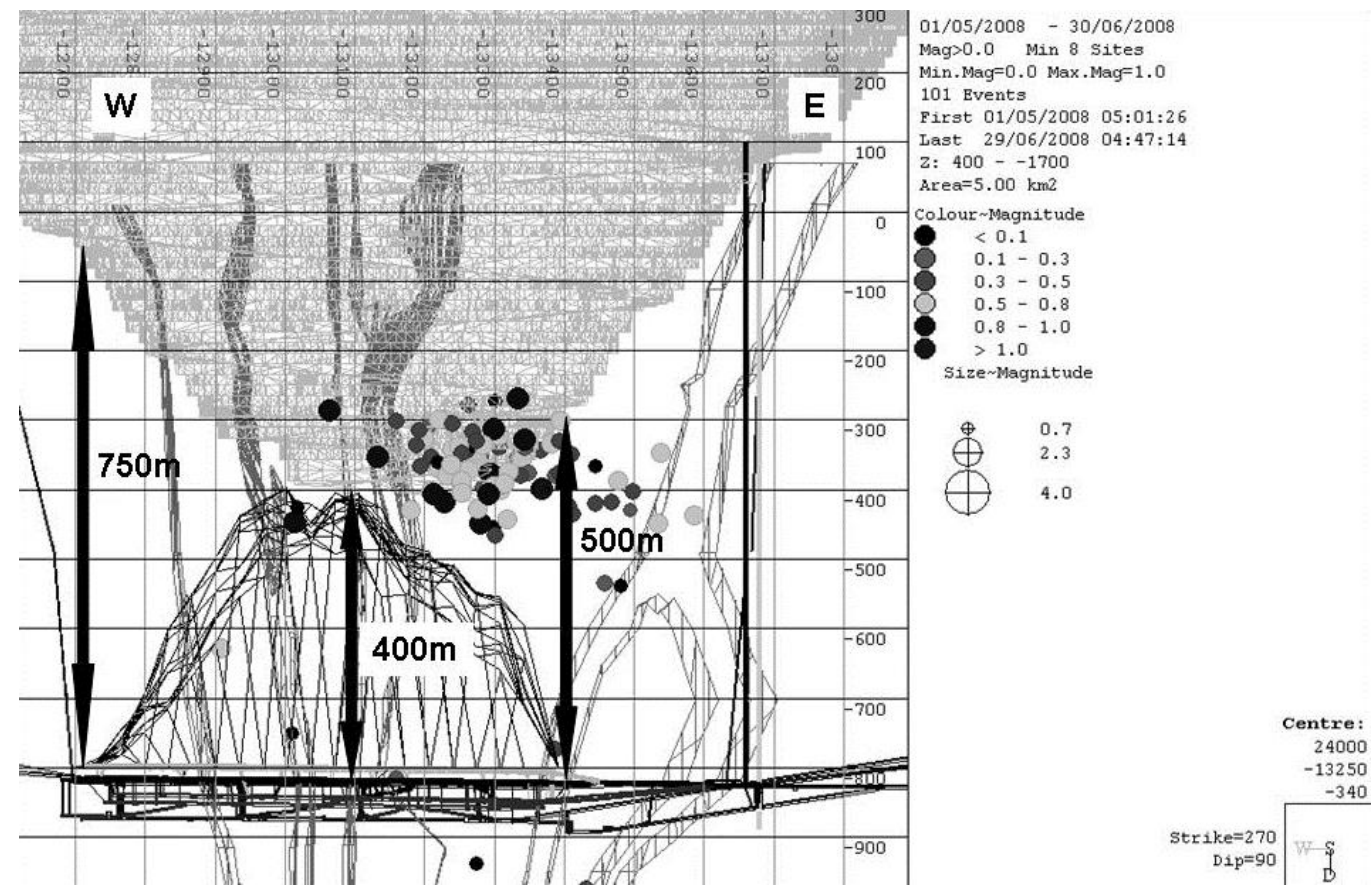

Figure 2 Estimated cave back position in May 2004 
Figure 2 shows the estimated cave position in May 2004 when the cave broke into the open pit in the central section. The maximum height of the cave in the central section was $400 \mathrm{~m}$. The maximum cave heights in the east and west were $500 \mathrm{~m}$ and $750 \mathrm{~m}$ respectively. The seismicity presented by this figure was recorded during May and June 2008 during the months when the cave broke into the open pit at the east part of the mine. The seismicity illustrated is not the complete seismicity that was associated with this breakthrough as too much seismicity would blur the picture. Still, this sample of seismicity indicates that it located in the east and at shallow elevations above the elevation of $-400 \mathrm{~m}$. The next interesting fact about this seismicity is that it was of rather large size magnitude (above magnitude 0.0) while at the time most of the seismicity associated with the cave expansion was of magnitude lower than 0.0 .

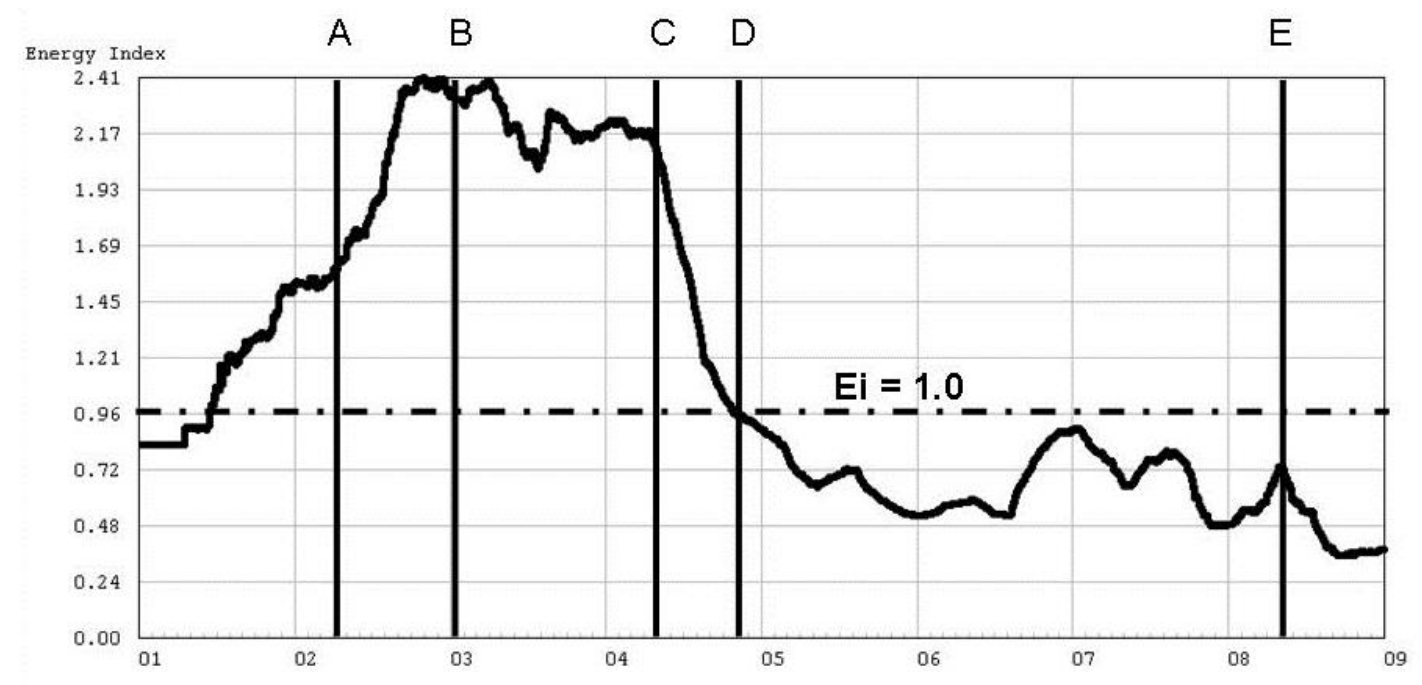

Figure 3 PMC stress history from 2001 to 2009

Figure 3 shows the seismic energy index history for the whole mine, from the beginning of 2001 until end of December 2008. Energy index is defined as the ratio of the seismic energy of an event to its mean value for a given seismic moment for this event. The energy index graph represents the stress regime and in this case relates its changes and values to different stages of the caving process. To start with, the stress levels during 2001 were already above the average value (1.0). This stress increase was the result of the development mining. The start of the caving process in April 2002 (A) was associated with a rapid stress increase that lasted until the failure of the crown pillar at the end of 2002 (B). The maximum stress time period continued until the cave broke through into the open pit in May 2004 (C). From then on the stresses started to decrease to reach the average level by the end of 2004 which was just after the major failure in the open pit (D) which took place during October 2004. At that stage the stress decrease rates were faster than the increase rates after the initiation of the caving process. The stress increase from mid 2006 was associated with the cave developing faster at the east side of the mine. The cave in the east broke into the pit during May and June 2008 (E). The stress increase due to the development mining phase was very low when compared to the stress increase induced by the caving process. The stress level during the east breakthrough was significantly lower than during the initial breakthrough $(\mathrm{C})$.

The initiation of the stress caving process and its influence on the induced seismicity is already described elsewhere (Glazer and Hepworth, 2004, 2005), as is the crown pillar failure mechanism (Glazer and Hepworth, 2006). The major failure of the open pit north wall has also been well documented (Brummer et al., 2006; Sainsbury et al., 2008). Various applications of mine seismology in monitoring the Palabora Mining Company cave progress have also been published (Glazer, 2007, 2008; Glazer and Townsend, 2008). For this reason in this paper the focus will only be on the similarities and differences regarding the two breakthrough events as deduced from the recorded seismicity. 


\section{Energy index and elevation changes associated with the cave breakthrough events}

Figure 4 illustrates the energy index history and the average monthly seismicity elevation changes for the central section above the extraction level from the beginning of 2001 until the end of 2005. Figure 5 shows these two values for the east and above the extraction level from the beginning of 2005 to the end of October 2008. The vertical scales for Figures 4 and 5 are the same.

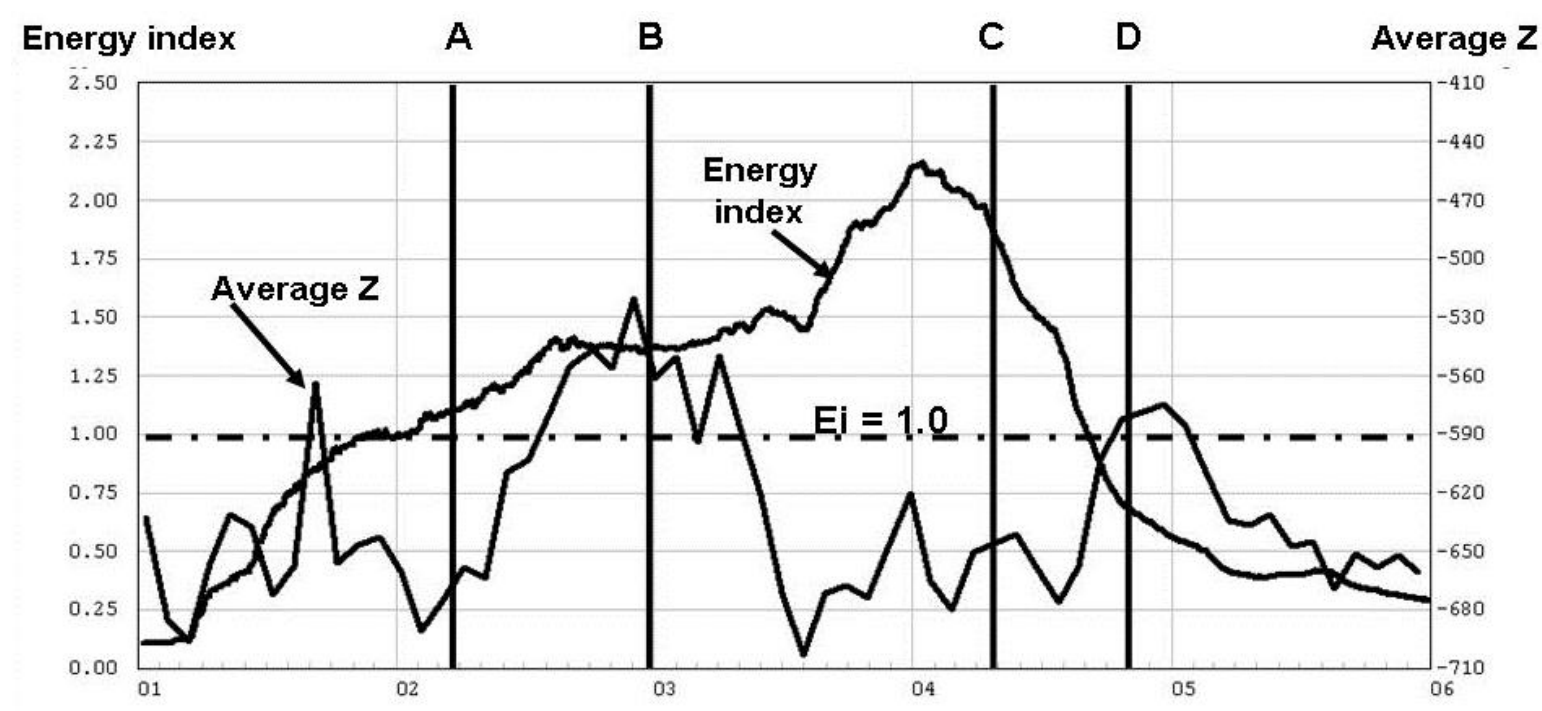

Figure 4 Central breakthrough, energy index and seismicity elevations

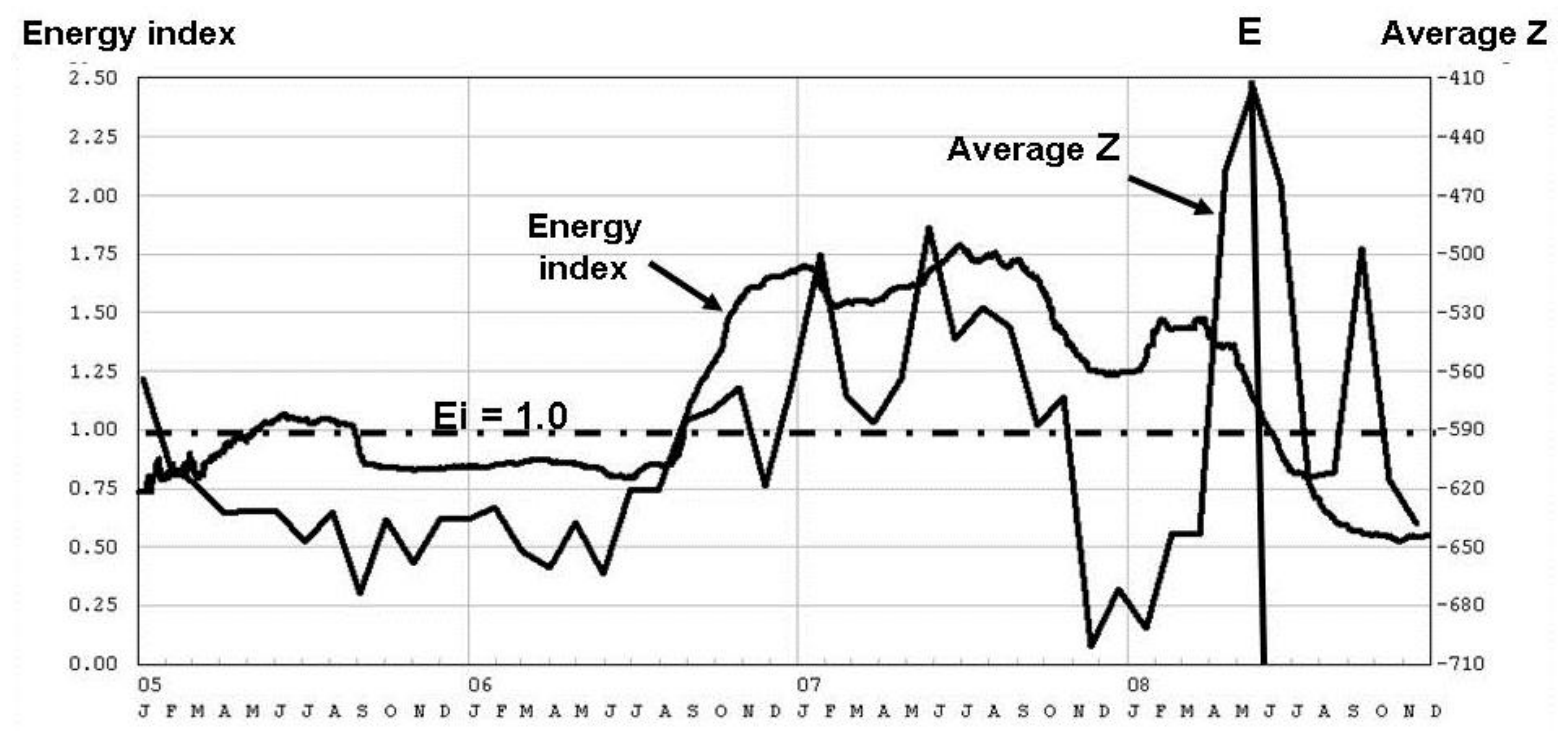

Figure 5 East breakthrough, energy index and seismicity elevations

Above the mine level in the central part of the mine (Figure 4) the energy index at the beginning of 2001 was low and then increased rapidly to reach the mean value of 1.0 by the end of 2002 . This stress increase lasted to about the end of 2003. The rate of stress release which started just before the initial cave breakthrough during 2004 was higher than the rate of stress increase during 2001 and 2002. The mean energy index value of 1.0 was reached at the end of 2004. The average $\mathrm{Z}$ graphs in Figure 4 and 5 illustrate the seismicity elevation trends that are based on monthly trends. In case of the rock mass located above the mine it is clear that the initiation of the stress caving process (A) resulted in more seismicity taking place closer to the cave. With the cave expanding after the initiation process (A), the seismicity started to migrate upwards. The 
failure of the crown pillar by the end of 2002 (B) is also evident. At this stage the seismicity reached its shallowest elevation for this period. After the failure the seismicity migrated downwards. This downward migration lasted only six months. From mid 2003 the seismicity started to migrate upwards and then reached its next shallowest elevation at the time of the failure in the open pit (D). This second period was then followed by another downward migration.

In the east above the mine (Figure 5) from about June 2006, there was a continuous stress increase which up to the end of 2006 was rapid. From the beginning of 2007 until about March 2008 the stresses remained fairly constant at about the same level. From April 2008 there was a rapid stress release as the energy index had already reached the mean value of 1.0 by June/July 2008. From mid 2006 until mid 2007 there was a general upward migration of seismicity with the seismicity being at the shallowest elevation during the first half of 2007. During the second half of 2007 there was a rapid downward migration of seismicity. From January 2007 to February 2008 the production from the east sector of the mine decreased by nearly $40 \%$. During this time the average monthly seismicity elevation decreased by nearly $200 \mathrm{~m}$. During March 2008, in relation to February 2008, the production rate increased by $35 \%$. As a result the downward migration was then reversed by a very rapid upward migration of seismicity with minimum elevations reached during April and May 2008. The subsequent downward seismicity migration (during June, July and August 2008) was of the same magnitude as the previous upward migration.

A direct comparison of the maximum energy index values indicates that the maximum energy index value during the initial (central) breakthrough was at 3.1 (Figure 4) while during the east breakthrough the maximum value of the energy index was lower at 1.75 (Figure 5). This suggests that at the end of 2003 just before the initial breakthrough the stress levels around the mine where higher than those during mid 2007 before the east breakthrough. This must be correct as by mid 2007 the rock mass around the cave had to be much more broken and fractured than it was at the end of 2003. By the end of 2003 the caving process had been in operation for just 20 months while by mid 2007 the caving process had been in operation for nearly 70 months.

Regarding the monthly seismicity elevations the minimum elevation at the time of the initial breakthrough was at about $-515 \mathrm{~m}$ and during the east breakthrough at $-490 \mathrm{~m}$ (mid 2007) and then at $-410 \mathrm{~m}$ (May 2008). The seismicity elevations during the east breakthrough during May 2008 were shallower than during the crown pillar failure at the end of 2003. In fact they are the shallowest for the entire history of the mine up to the end of 2008. As with the energy index this must be correct. The maximum height of the cave at its central part is $400 \mathrm{~m}$ while at the east it is $100 \mathrm{~m}$ higher (see Figure 2). The differences between the stress levels and the maximum upward migration of seismicity during these two breakthrough events are obvious and easily derived from other information than just seismicity. The breakthrough has been confirmed using seismic data based on two different seismic parameters.

\section{Seismic energy releases associated with the breakthrough events}

Figure 6 shows the energy index and the cumulative seismic energy release time histories for the central part of the mine, while Figure 7 shows these two parameters for the east part of the mine. In both cases the time histories are for the rock mass located above the mine. In order to eliminate seismic energy releases due to development mining (draw bells were completed in August 2004) an elevation range from - $200 \mathrm{~m}$ down to $-700 \mathrm{~m}$ has been used for the central part of the mine. Figures 6 and 7 have the same scales for the energy indexes as well as for the cumulative seismic energy releases. At the central part of the mine (Figure 6) during the 25 month time period lasting from April 2002 (cave initiation) until the cave breakthrough, there was a continuous stress build-up that was associated with a continuous but low seismic energy release. From the time of the central breakthrough (May 2004) the stresses started to decrease and there was a rapid increase in released seismic energy lasting five months. In fact this rapid stress release period accounts for about $50 \%$ of the total seismic energy that was released from the beginning of 2002. In the east (Figure 7) there was a continuous stress increase lasting from August 2006 to April 2008 (20 months) that was associated with a continuous but low seismic energy release (similar to the central part of the mine). From April 2008 until June 2008 during a rapid stress decrease lasting only three months, there was also a rapid increase in released seismic energy. During this period more than $90 \%$ of the total seismic energy was released. 


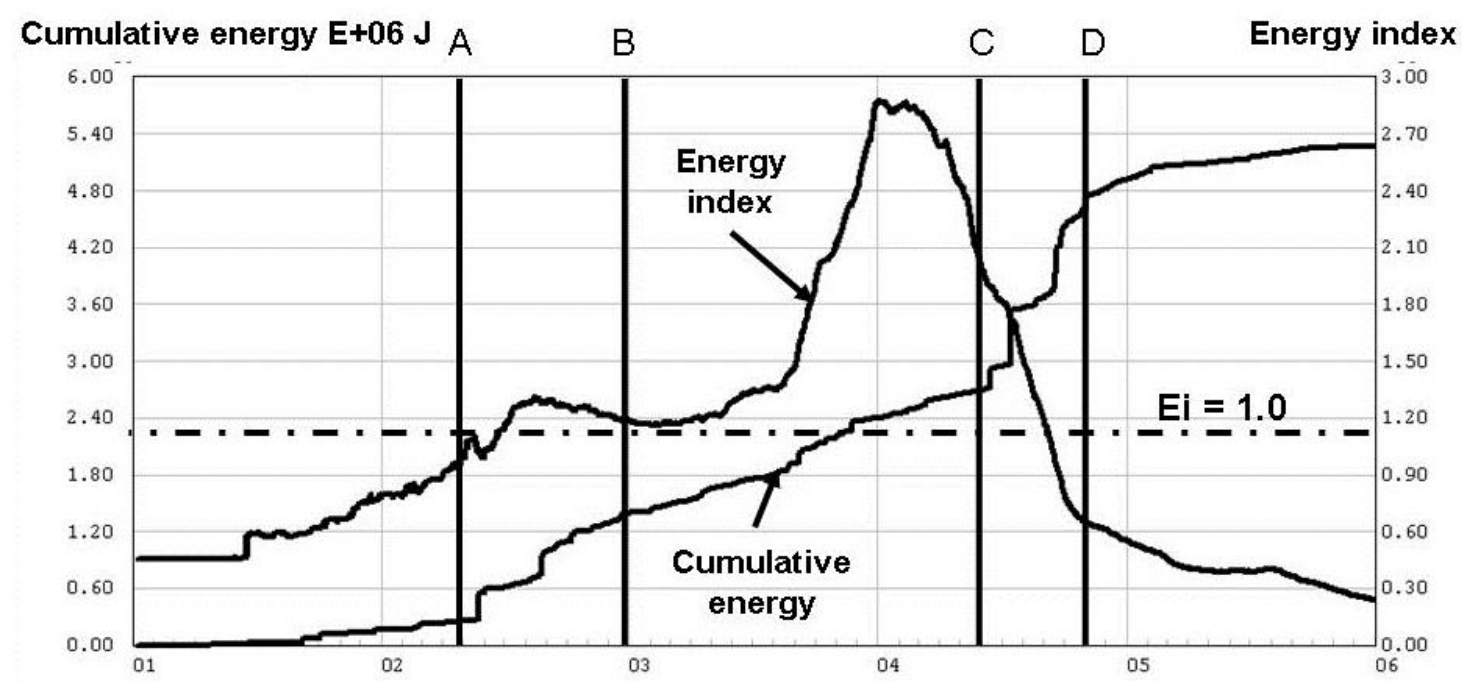

Figure 6 Central breakthrough, energy index and cumulative energy release

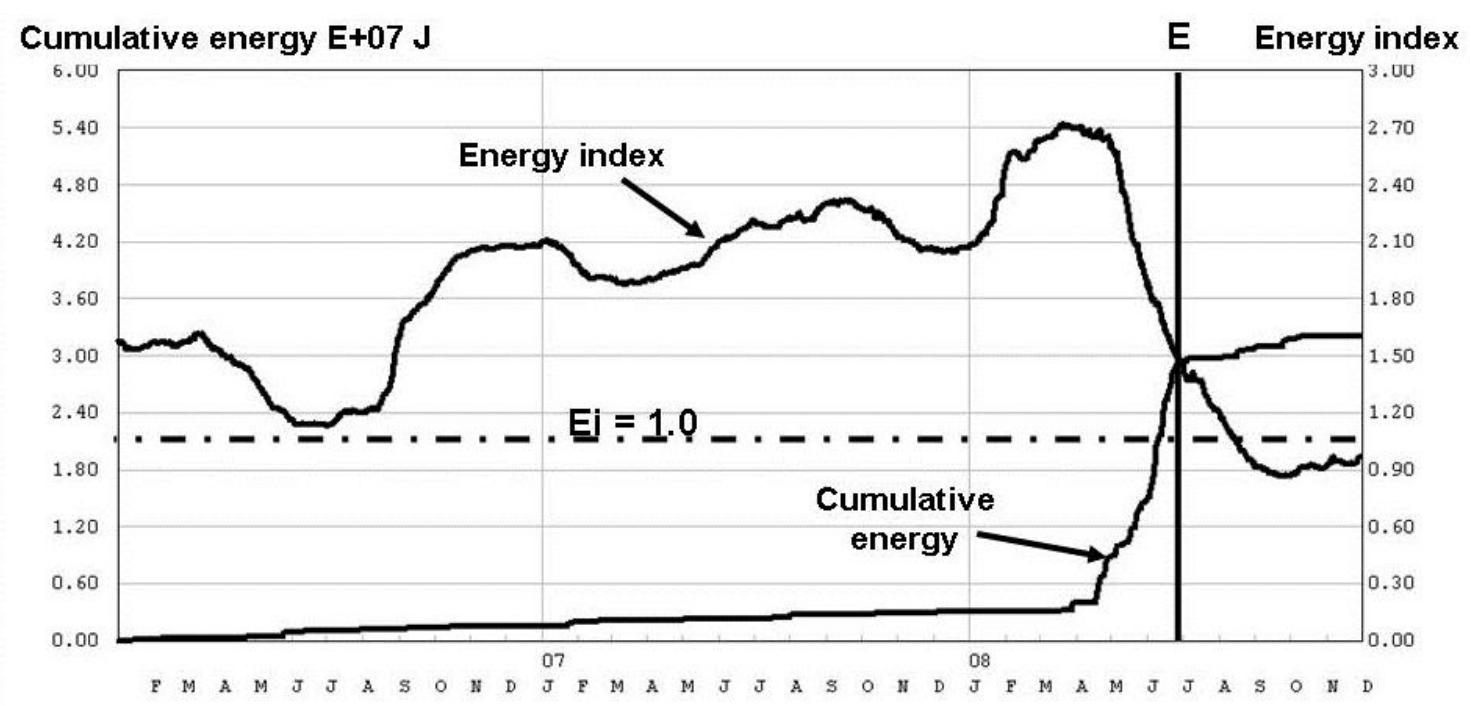

Figure 7 East breakthrough, energy index and cumulative energy release

It is reasonable to expect that during the time periods when the stresses are building up there will be less seismic energy released and consequently during a stress release period there will be more seismic energy released. Furthermore, one should expect that when the stresses are higher the energy releases will be higher than for a lower stress environment. Consequently, a higher stress release should release more seismic energy than the lower stress release. In the case of the central breakthrough the high stress lasted for 25 months and during this period the seismic energy release amounted to $21.00 \mathrm{E}+06 \mathrm{~J}$, which is an average of $0.84 \mathrm{E}+06 \mathrm{~J}$ per month. In case of the east breakthrough the high stress lasted for 20 months and during this time period the seismic energy release totalled $2.40 \mathrm{E}+06 \mathrm{~J}$ which is an average of $0.12 \mathrm{E}+06 \mathrm{~J}$ per month. As indicated by the energy index values the stresses at the central part of the mine prior to the initial breakthrough were higher than those at the east prior to the east breakthrough. During the stress build-up period prior to the central breakthrough the seismic energy release was nearly nine times higher than during the high stress period before the east breakthrough. During the stress release period after the central breakthrough the seismic energy release totalled $21.1 \mathrm{E}+06 \mathrm{~J}(4.22 \mathrm{E}+06 \mathrm{~J}$ per month). After the east breakthrough the seismic energy release amounted to $21.9 \mathrm{E}+06 \mathrm{~J}(7.30 \mathrm{E}+06 \mathrm{~J}$ per month). 


\section{Seismic deformations associated with the breakthrough events}

Figure 8 shows the energy index and the cumulative seismic moment time histories for the central part of the mine, while Figure 9 shows these two parameters for the east part of the mine. In both cases the time histories are for the rock mass located above the mine. In order to eliminate amounts of seismic moment due to development mining an elevation range from $-200 \mathrm{~m}$ down to $-700 \mathrm{~m}$ has been used for the central part of the mine. Figures 8 and 9 have the same scales for the energy indexes as well as for the cumulative seismic moment. At the central part of the mine (Figure 8) during the time period lasting 25 months from April 2002 (from cave initiation) until the cave breakthrough (C) there was a continuous stress build-up that was associated with a continuous but low seismic deformation rate. From the time of the central breakthrough (May 2004) when the stresses started to decrease there was an increase in seismic deformation lasting five months. At the east (Figure 9) there was a continuous stress increase lasting from August 2006 to April 2008 (20 months) that was associated with a continuous but low seismic deformation rate, just as at the central part of the mine. From April 2008 until June 2008 during the rapid stress decrease, which lasted only three months, there was also an increase in seismic deformation rates.

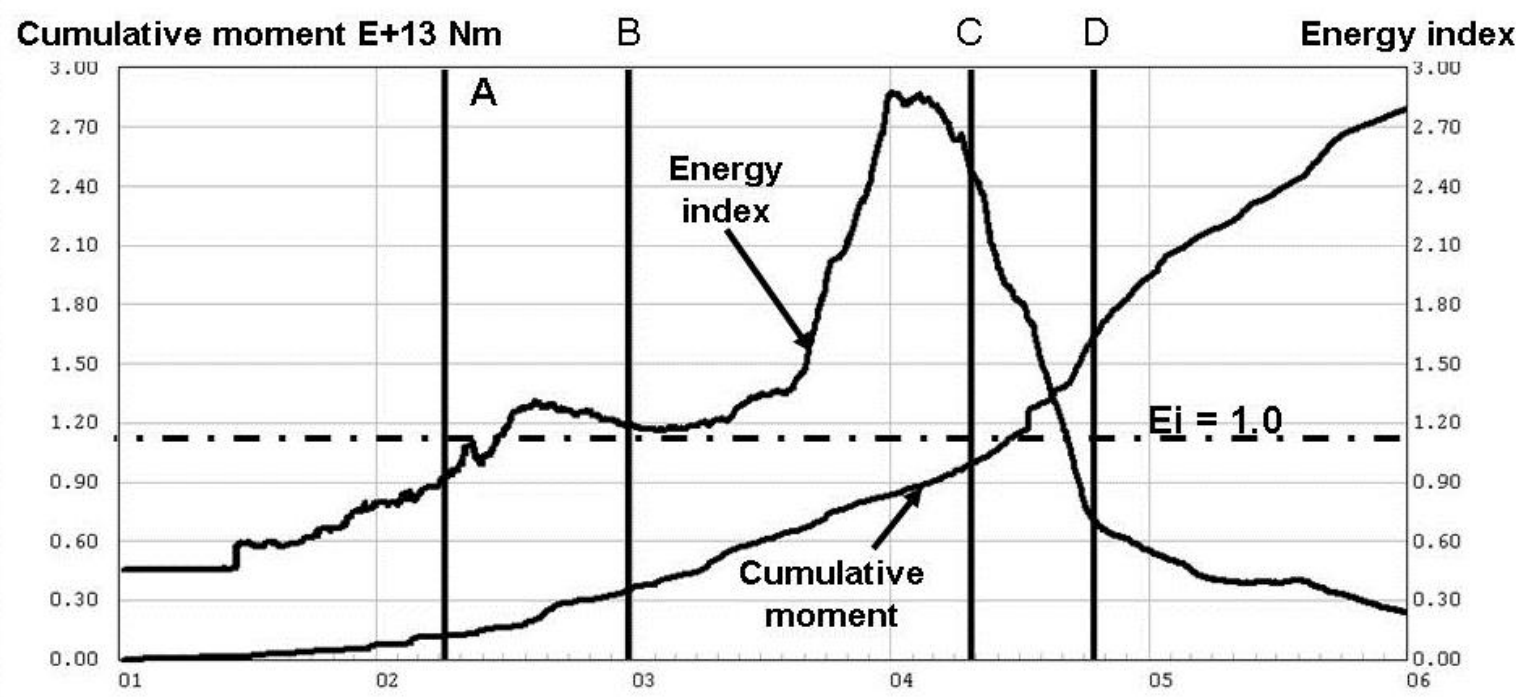

Figure 8 Central breakthrough, energy index and cumulative seismic moment

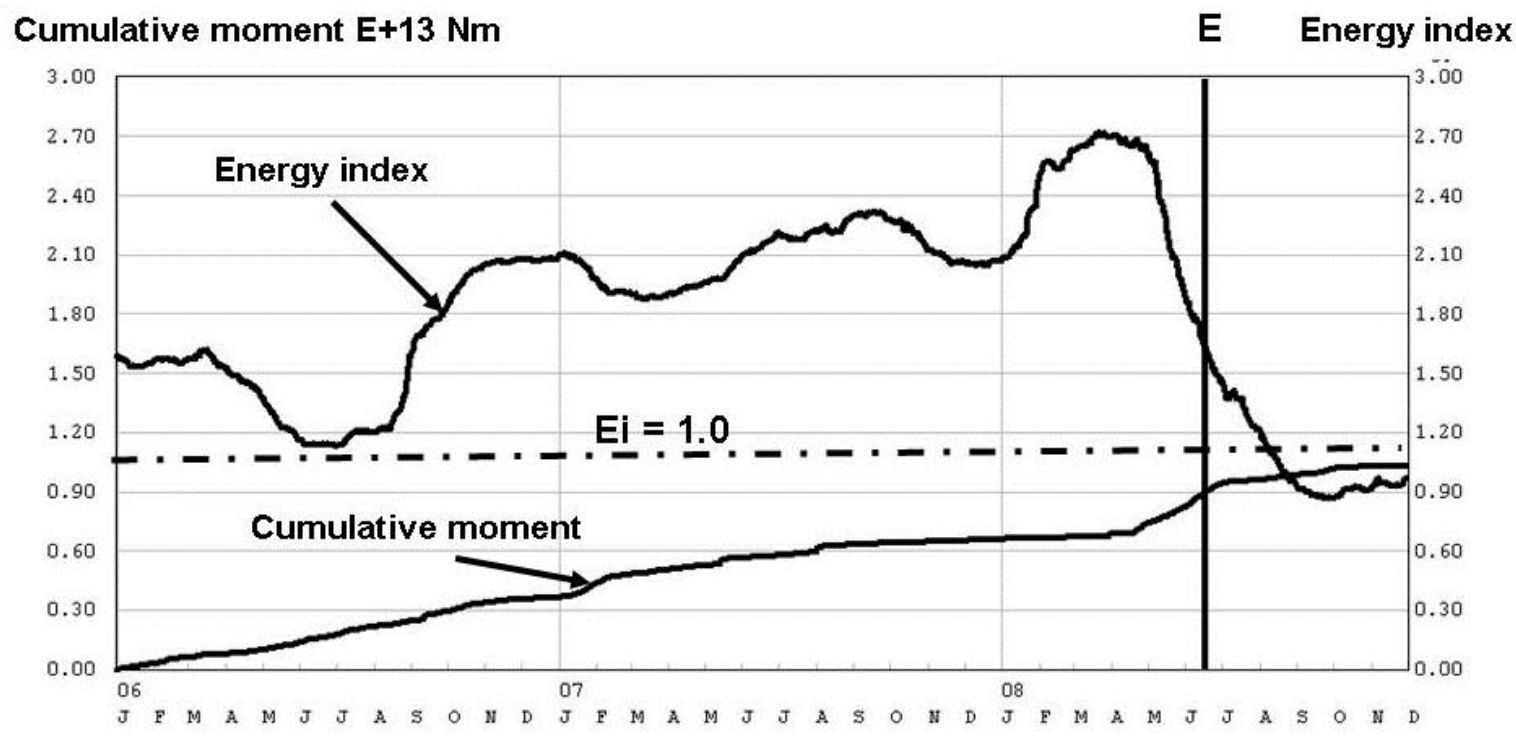

Figure 9 East breakthrough, energy index and cumulative seismic moment 
In the case of the central breakthrough the high stress lasted for 25 months and during this time the cumulative seismic deformation reached the value of $9.70 \mathrm{E}+12 \mathrm{Nm}$, so the average monthly deformation rate for that time period was $0.39 \mathrm{E}+12 \mathrm{Nm}$. In case of the east breakthrough the high stress lasted for 20 months and during this time the seismic moment accumulated to $5.31 \mathrm{E}+06 \mathrm{Nm}$ which gives an average of $0.27 \mathrm{E}+06 \mathrm{Nm}$ per month. As indicated by the energy index values the stresses at the central part of the mine prior to the initial breakthrough were higher than those in the east prior to the east breakthrough. During the stress build up period prior to the central breakthrough the seismic energy release was nearly nine times higher than during the higher stress time period before the east breakthrough, but the seismic deformation associated with the central breakthrough was only twice that which was associated with the east breakthrough. During the high stress release period after the central breakthrough the seismic moment totalled at $5.6 \mathrm{E}+12 \mathrm{Nm} \mathrm{J}(1.12 \mathrm{E}+12 \mathrm{Nm}$ per month). During the east breakthrough the seismic moment amounted to $2.42 \mathrm{E}+12 \mathrm{Nm}(0.81 \mathrm{E}+12 \mathrm{Nm}$ per month), which is half of that associated with the central breakthrough. During these two rapid stress releases the amounts of released seismic energy were similar, but there were less than half of the seismic deformations associated with the east breakthrough than with the initial breakthrough.

\section{$5 \quad$ Seismicity and production stoppages}

Production stoppages, although detrimental for mine revenue, do however, also provide some very useful information about the expansion void. From the beginning of 2002 until the end of 2008 there were seven production stoppages that lasted for a few days each. In each case the daily seismic activity rates for the whole mine decreased when production from the cave stopped, even for just a couple of days. Such a rapid rock mass reaction to a relatively short production stoppage when observed for the first time was unexpected, as normally the rock mass response to any type of mining activity is delayed. The most logical explanation is that there was no expansion void on top of the cave. In this event, even for very short periods when no tonnes are pulled from the cave, the cave expansion will stop, as there is no place for the material to cave in to. Once the drawing of cave material resumes, the caving process immediately commences with material caving into the void created. From this a more general relationship might be concluded. The larger the expansion void, the longer will be the delay in the rock mass response to changes in the production rate. If the production draw rate is always kept lower than the natural cave progression rate, there should be a minimal, or no expansion void. The rapid response of the seismicity to changes in the production rate suggests that Palabora was always pulling at a rate lower than the natural cave expansion rate. Thus this seismic data tends to support the earlier estimation of the natural cave expansion rate. Before the initial break through there were five production stoppages and in each case the seismicity decreased virtually on the first non-production day. From this it was concluded that there was no expansion void above the maximum elevation of the cave. The cave broke through the base of the open pit in April/May 2004 and as expected this took place with no immediate dramatic effects. On the contrary, this breakthrough was at first difficult to notice. Only by June/July 2004 the open pit started to show evidence that the breakthrough had already taken place (note: the cracking on the higher benches was noticed first on 31 March 2004).

The second influence on the seismicity is directly connected with the subsequent restarting of production after a couple of days. After the period of non-production the resuming of production in all seven cases resulted in larger size seismic energy releases that were associated with restarting the caving process. It is interesting to note that most of this large size seismicity took place in the east parts of the mine. This is because from about 2003 the stresses at the east side of the mine were constantly higher than those at the west. Figure 10 demonstrates the relationship between the changing stress levels over time around the cave, which are illustrated by the energy index time history and the amounts of seismic energy released (vertical bars), directly after restarting the caving process. This figure is based on seismic data recorded for the whole mine. 


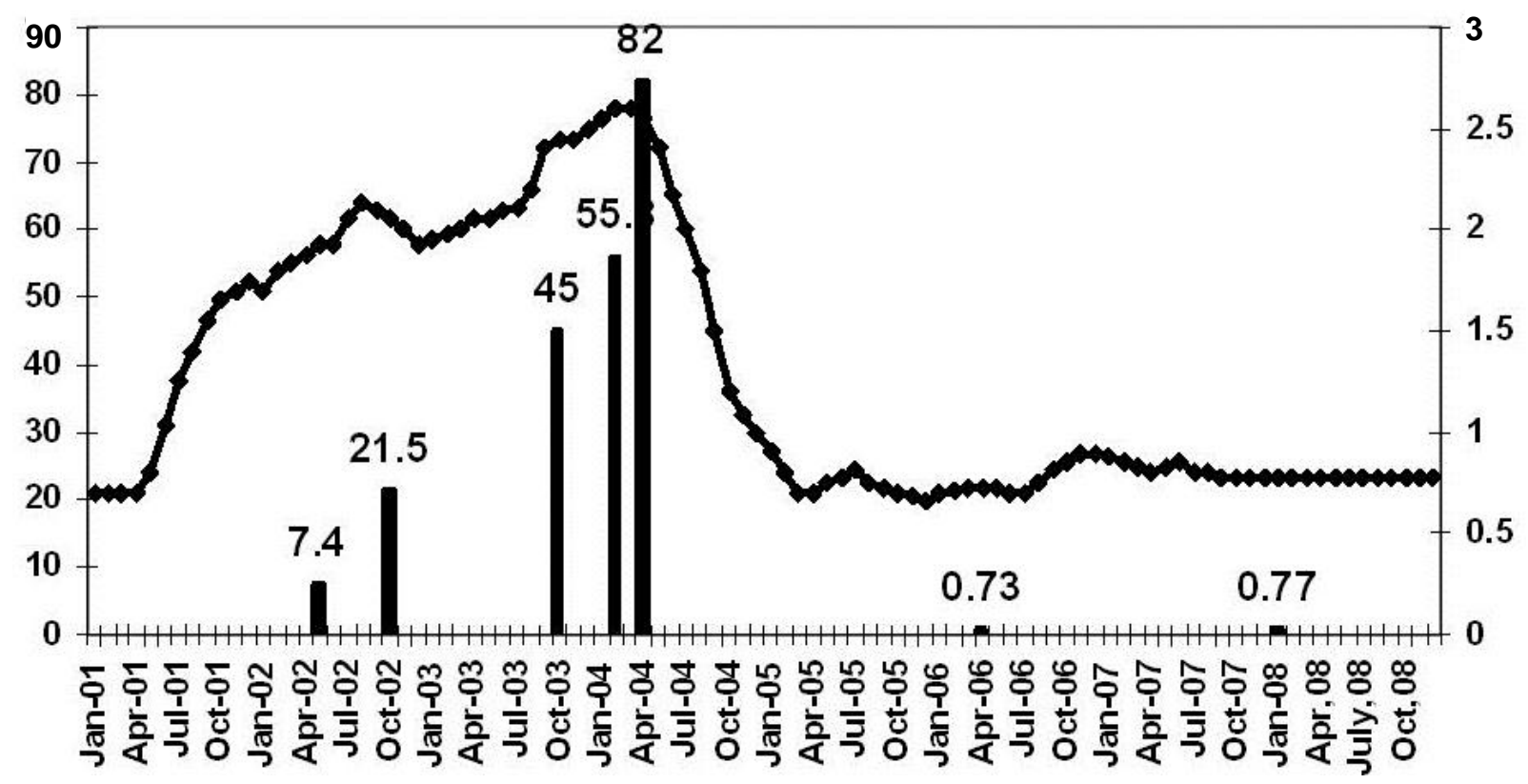

Figure 10 Seismic energy releases after re-starting production

Figure 10 indicates that the resuming of production while the stresses around the mine are high is associated with an increased seismic hazard. The other conclusion that is to be drawn from the data illustrated by this figure is the fact that the higher the stresses around the cave, the higher will be the seismic energy release associated with the restarting of the cave. After the initial break through there were two more production stoppages, the first in April 2006 and then the second in January 2008. Analysis of the general relationship between the production rates and the seismicity as well of the two production stoppages that took place after the initial breakthrough and their influence on seismicity indicates that at the east there was no expansion void during the period from the beginning of 2005 up to the break through during mid 2008.

\section{Percentages of seismicity above the mine}

Locations of seismicity are generally not as good as expected. This is usually due to the fact that most of the seismicity locates outside of the seismic network. All recorded events carry useful information that has to be extracted, but taking into account their location ambiguity. For this reason the whole data set is usually divided into such subsets for which accurate location is no longer as important. If the two data subsets divide the entire seismicity into that locating above and below the extraction level, then it can be assumed that most of this data fulfils this simple requirement. If a small percentage of this data still does not fulfil this requirement then it does not really matter. Statistically it can be expected that the same number of events that took place above the mine will be included in the subset that contains seismicity from below the mine as the number of events that took place below the mine will be included in the subset above the mine. Furthermore, when one deals with large data sets and for interpretation purposes uses only their trends, then this final output has gone through such smoothing processes that the remaining location ambiguity is of no significance. In addition when the output is in percentages, the network performance (number of stations off line) then does not influence the final results. If for a period the network is down or some of its stations are not operational, then it influences the amounts of recorded seismicity above as well as below the mine in a similar manner. Analysis of trends and changes in time in percentages of seismicity, released seismic energy and seismic deformations taking place above the mine proved to be a very reliable indicator of the caving process. 


\section{Percentages of seismic deformation above the mine}

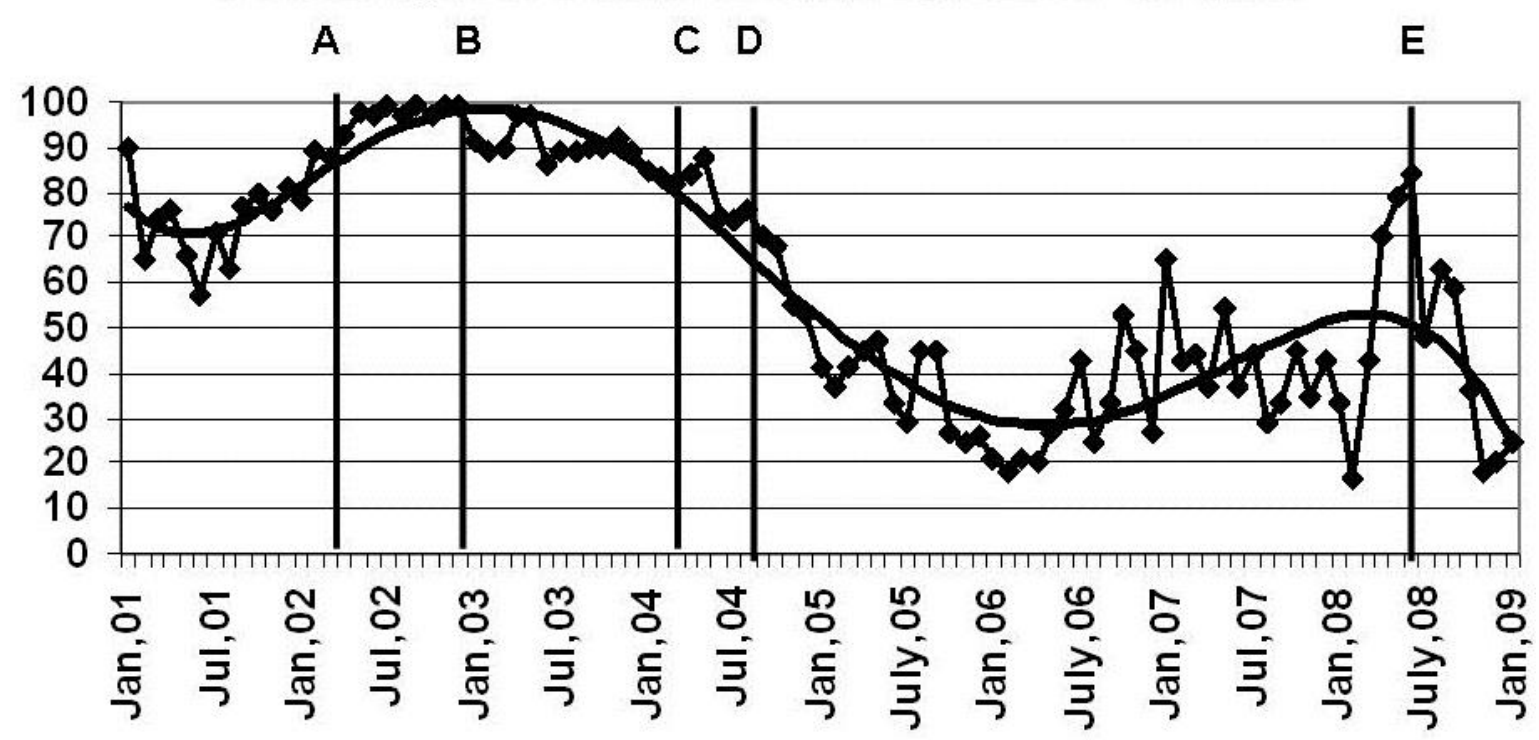

Figure 11 Percentages of seismic deformation above the whole mine

Figure 11 shows the percentages of monthly seismic deformation rates above the whole mine together with a trend line for these percentages (continuous line). The maximum deformation rates above the mine are associated with the caving process. After the cave broke through into the open pit the percentages of seismic deformation above the mine level dropped from about 80\% (June 2004) to less than 50\% in January 2005. This decrease continued until April 2006 when only about $20 \%$ of the observed seismic deformation was taking place above the mine level. From May 2006 until May 2007 the amount of seismic deformation taking place above the mine increased to about 50\%. This value for December 2007 was back down at 35\%. This indicates that at that time the cave was still expanding on the east side of the footprint. During January and February 2008 the percentages of seismic deformation above the mine decreased further to $10 \%$. This amount increased during March 2008 to more than 40\% and then during April and May 2008 was close to $70 \%$. During June 2008, 84\% of the total monthly seismic deformation took place above the mine. During July, August, September, October and November 2008, the amount of seismic deformation taking place above the mine decreased to $48 \%, 53 \% 54 \%, 36 \%$ and 18\% respectively. Analysis of the percentages of seismic monthly rates above the mine indicates that a new process started around about June 2006. About this time the continuous decreasing trend in the amounts of seismicity, seismic energy released as well as that of seismic deformation taking place above the mine, that lasted in each case for about two years then terminated. In all three cases from then on there was more seismicity, seismic energy release as well as seismic deformation taking place above the mine. An analysis of percentages of seismicity taking place above the east part of the mine indicated that as from June 2006 there was a general increase in the seismic activity above the eastern part of the mine footprint. Less evident were the increases in the amounts of seismicity, but in all three cases the percentage increases during April, May and June 2008 were evident. During this time period more than $50 \%$ of seismicity, more than $90 \%$ of the seismic energy release and more than $80 \%$ of seismic deformation were taking place above the mine footprint. The subsequent decrease in the amounts of seismic activity after June/July 2008 was, in all three cases, very prominent.

\section{Conclusions}

This detailed back analysis of the initial and east pillar failures at Palabora are based primarily on seismic data. The other cave monitoring devices installed in boreholes that could provide data had been lost during 2003 as a consequence of the response of the rock mass to mining. The initial breakthrough and the east breakthrough took place 25 months and 50 months respectively after the caving process was initiated. For this reason the rock mass conditions during these two breakthrough events had to be very different. However, the analysed seismic data associated with these two breakthrough events indicates a lot of similarities and only some minor differences. To start with the energy index time histories of the two 
breakthrough events are very similar indicating a stress increase prior to the breakthrough with a rapid stress release after the breakthrough. In case of the initial breakthrough the stress increase lasted close to 24 months (from the beginning of 2002 until the end of 2003).The time period of high stresses associated with the east breakthrough was very similar as the stresses started to increase in June 2006 and then the stress release started in April 2008. The main difference is the stress levels. Based on the energy index time histories the stress levels prior to the initial breakthrough were higher than those prior to the east breakthrough. This observation is confirmed by the seismic energy release sizes due to the restarting of production after a couple of days of non-production. The two time periods of stress release are also very similar, five and three months respectively. The rapid stress release period in both cases was about six times shorter from the time while the stresses were high. In both cases the pillar failure and then the breakthrough resulted in major changes in the stress patterns around the mine. After the failure of the crown pillar larger size seismic energy releases started to appear below the extraction level. When the east pillar failed and broke through there were also some larger seismic energy releases taking place below the extraction level. In both cases the breakthrough events resulted in an increase in the seismic hazard. There is a lot of similarity as far as stress changes (as indicated by the energy index time histories), seismicity migration, seismic energy release as well as seismic deformation patterns are concerned. There are also some differences but they seem easy to explain as the initial breakthrough took place 25 months after the stress caving process was initiated while in case of the east breakthrough this time span had increased by a further four years. The continuous caving process during these four additional years undoubtedly resulted in significant changes to the condition of the rock mass around the cave that gave rise to these differences.

In both cases the breakthrough manifested itself by similar seismicity patterns:

- prior to the breakthrough the stress as indicated by the energy index increased

- during the breakthrough the stresses as indicated by the energy index decreased rapidly

- prior to the breakthrough the seismicity migrated upwards

- during the breakthrough the seismicity migrated downwards

- after the both breakthrough events there was some larger size seismicity taking place below the production level

- prior to the breakthrough the amounts of seismicity, as well as seismic deformation and seismic energy release above the extraction level were high (above 80\%)

- during the breakthrough the amounts of seismicity, as well as seismic deformation and seismic energy release above the mine decreased rapidly.

The foregoing analyses not only illustrate the fact that seismic data analysis can be successfully used to monitor the caving process, but also confirm how reliable it is. Finally it is interesting to note that practically all of the illustrated analyses of recorded seismicity are independent of the location accuracy. When the data input catalogues consists of all recorded data like in the cases of energy index time histories or cumulative values of released seismic energy or seismic moment or when analysing percentages of various seismic activities taking place above the mine the locations of individual seismic events become irrelevant. When the production was stopped only the seismic activity rates changes were important, even when seismic migration trends were analysed only the monthly average seismicity elevations were taken into account. Again in both these two cases accurate location of each event was not that important. Accurate locations of seismicity are very difficult to achieve. For this seismic sensors must be not only located all around the mine (or cave) but also placed at different elevations that vary from below of the mine right to the surface above the mine. Such ideal sensor configurations are often not possible to implement due to technical problems but are also not viable from the expenditure required.

\section{Acknowledgements}

The authors wish to thank the Palabora Mining Company Management for granting permission to publish this paper. 


\section{References}

Brummer, R.K., Li, H. and Moss, A. (2006) The transition from open pit to underground mining: An unusual slope failure at Palabora, The South African Institute of Mining and Metallurgy, International Symposium on Stability of Rock Slopes in Open Pit Mining and Civil Engineering, April, pp. 411-420.

Glazer, S.N. and Hepworth, N. (2004) Seismic Monitoring of Block Cave Crown Pillar - Palabora Mining Company, RSA, in Proceedings MassMin 2004, K. Karzulowicz and M.A. Alfaro (eds), Mineral Chilena, Santiago, Chile, pp. 565-569.

Glazer, S.N. and Hepworth, N. (2005) Seismicity Induced by Cave Mining, Palabora Experience, in Proceedings Sixth International Symposium on Rockbursts and Seismicity in Mines, Y. Potvin, and M. Hudyma (eds), Australian Centre for Geomechanics, pp. 281-289.

Glazer, S.N. and Hepworth, N. (2006) Crown Pillar Failure Mechanism - Case Study Based on Seismic Data from Palabora, in Mining Technology 2006, Institute of Minerals and Mining, Published by Maney, Vol. 115, No. 2, pp. 75-84.

Glazer, S.N. (2007) Applications of mine Seismology Methods in Block Cave Mining, in Proceedings 1st International Symposium on Block and Sub-level Caving, Cape Town, October 2007, Symposium Series S49, SAIMM, pp. 281-301.

Glazer, S.N. (2008) Seismically Active Volume Around the Cave and its Relation to the Caving Stages, in Proceedings 5th International Conference and Exhibition on Mass Mining, H. Schunnesson and E. Nordlung (eds), Luleå, Sweden, 9-11 June 2008, pp. 983-992.

Glazer, S.N. and Townsend, P. (2008) The Application of Seismic Monitoring to the Future Lift 2 Development at Palabora Mining Company, in Proceedings 5th International Conference and Exhibition on Mass Mining, H. Schunnesson and E. Nordlung (eds), Luleå, Sweden, 9-11 June 2008, pp. 919-930.

Sainsbury, B., Pierce, M.E. and Mas Ivars, D. (2008) Analysis of caving Behaviour Using a Synthetic Rock Mass Ubiquitous Joint Rock Mass Modelling Technique, in Proceedings 1st Southern Hemisphere International Rock Mechanics Symposium, SHIRMS08, Y. Potvin, J. Carter, A. Dyskin, and R. Jeffrey (eds), Australian Centre for Geomechanics, Vol. 1: Mining and Civil, pp. 243-253. 